\title{
STUDYING OF INTERCONNECTIONS OF MORPHOLOGICAL FUNCTIONAL INDICATORS OF STUDENTS, WHO PRACTICE MARTIAL ARTS
}

Podrigalo L.V., Iermakov S.S., Alekseev A.F., Rovnaya O.A.

Kharkov State Academy of Physical Culture

\begin{abstract}
Purpose: to study interconnections of students' morphological functional indicators and their influence on level of sportsmanship. Material: in the research 17 students, practicing martial arts, participated. 62 indicators were determined: anthropometrical, goniometrical criteria of arms joints' status; tapping test and maximal frequency of grabs in impulse mode. Results: we found that maximal contribution in system is made by hand dynamometry of right and left hands, body length and mass, chest circumference, width of shoulders; maximal frequency of grabs by right and left hands. It was confirmed that there are correlations between students' morphological functional indicators. The highest contribution to formation of functional system is characteristic for anthropometric indicators. Results of maximal grabs in impulse mode made rather sufficient contribution in system's formation that is confirmed by great quantity of correlations. Analysis of character, strength and orientation of correlations witnesses about informative potential of this test and permits to recommend it as screening for control of sportsmen's state. Conclusions: we determined that indicators of hand dynamometry system formation illustrate that for martial arts wrestlers strong grab was very important. It is ensured by strength of hand muscles.
\end{abstract}

Key words: martial arts, morphological functional, indicators, correlations, students.

\section{Introduction}

Achievement of high sportsmanship depends on the whole complex of indicators, among which important places are taken by peculiarities of physical condition and level of fitness. Besides their absolute values, when analyzing sportsmen's status, interconnections between them shall be considered. It permits to reflect the state of homeostasis and is an illustration of prognosis of sportsmen's success.

As on to day there has been sufficient quantity of works, devoted to this problem in different kinds of sports. For example, Baláš, J. et al. [7], who studied body composition, muscular strength and endurance of sport mountaineers, determined presence of correlations between these components. Authors outlined the most informative indicators, which included strength of grab, hanging on bent arms and fingers, content of fat, rock climbing experience (dispersion 97\%).

Studying men's body composition (members of baseball combined team of Poland), Yagello V. et al. [6] determined characteristic features of their somatic condition. The authors connect it with tactic and technical peculiarities of this kind of sports.

Kocharian T.N. et al. [2], analyzed specific features of morphological development of elite basketball players of different game roles. The authors determined regularities of decreasing of absolute sizes of body (longitudinal, transverse and perimeter) from central players to forwards and backs. They confirmed dependence of proportion types on basketball players' game roles.

Comparative analysis of power kind of sports' sportsmen' physical condition confirmed correlation between anthropometrical indicators and sportsmanship. Besides, the most informative indicators and physical condition indices were found [3, 11-13, 15-20].

The available results permit to conclude that studying of sportsmen's physical condition shall consider peculiarities of kind of sports. It permits to optimize the procedure of selection and substantially increase effectiveness of control and prognosis of sportsmen's success.

Coming from the above mentioned, the purpose of the research was to study morphological functional indicators of students (practicing martial arts) as factors of influence on level of sportsmanship.

\section{Material and methods}

In the research 17 students, practicing martial arts, participated. Mean age was (17.53 \pm 0.15$)$ years. Level of sportsmanship varied from sportsmen-beginners' to candidate masters of sports and masters of sports. The participants were representatives of strike kinds (karate, hand-to-hand fighting, thae-quan-do) and throw kinds of martial arts (Judo,

(c) Podrigalo L.V., lermakov S.S., Alekseev A.F.,

Rovnaya O.A., 2015

doi:10.15561/20755279.2015.0609 
Greco-Rome wrestling). Design of the research implied determination of 62 morphological and functional indicators. They included anthropometrical indicators (somatic-metric and physical-metric), reflecting general physical condition, status of upper and lower limbs. We conducted goniometric researches of amplitude of movements in upper limbs' joints. Results of tapping test were used as illustration of nervous system's liability. Peculiarities of martial arts conditioned interest to study of maximal frequency of hand's grab in impulse mode. For assessment of this quality we used electronic device "Kepai" (made in China). The methodic implied registration of maximal quantity of device's pressing during 10 seconds.

Statistical analysis of the received data was conducted with the help of licensed electronic tables Excel. On the base of the received results we built correlation matrix, which included coefficients by Pirson. For analysis we chose only confident dependences ( $r>0.482)$. Contribution of each indicator in system was assessed by indicator of system formation. This criterion was offered by Zosimov A.N. [21] for analysis of correlation matrixes. It reflects quantity of connections, formed by the tested indicator and their strength. The indicator is expressed in conventional units and calculated by formula:

$$
\mathrm{PS}=\sum \mathrm{rj} \cdot \mathrm{n}
$$

where, $\sum \mathrm{rj}$ - sum of values of significant correlation coefficients, formed by given indicator, $\mathrm{n}$ - quantity of significant correlations of given indicator of structure.

\section{Results of the research}

For comparative analysis we determined indicators of system formation for values, which are traditionally used in analysis of physical conditions: bode length and mass, chest circumference, width of shoulders, hand dynamometry by both hands, tapping test results and maximal frequency of grabs by both hands. The received results are shown in fig.1.

Indicator of system formation,

Conventional units

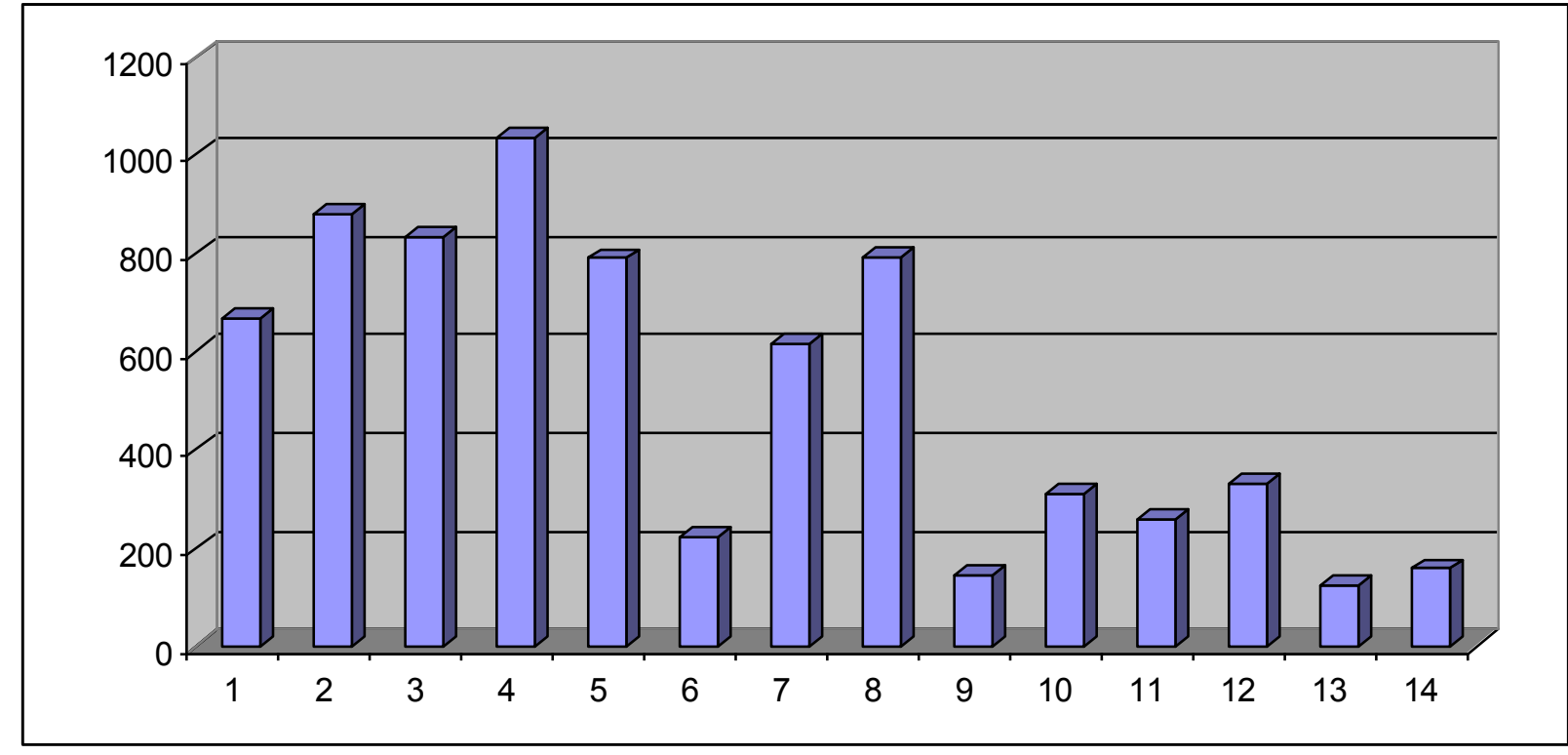

Criteria

Fig. 1. Value of system formation indicator of the tested criteria: 1 -body length; 2 -body mass; 3 - chest circumference; 4 - right hand dynamometry; 5 - left hand dynamometry; 6 - maximal frequency of grab by right hand; 7 - maximal frequency of grab by left hand; 8- width of shoulders; 9-14 - tapping test results - in every subtest accordingly.

We have determined that right hand dynamometry is characterized by maximal value (1036.48), second place is taken by body mass (878.18), then go chest circumference (832.28), width of shoulders (791.34), left hand dynamometry 
(789.10); body length (669.06). The seventh rank place is taken by maximal frequency of left hand grab (616.78). Results of this test's fulfillment by right hand are at $11^{\text {th }}$ place (221.11). Results of tapping test take 8-10 and 12-14rank places. Their values are within 330-124.

Contribution of anthropometric indicators in system illustrates importance of physical condition for success in martial arts. It is witnessed by closeness of system formation indicator of main physical condition values: body length, body mass, chest circumference and width of shoulders. The used indicators are integral criteria of physical condition, reflecting condition of muscular system. With it, in this context especially noticeable is the fact that system formation indicators decrease in the following order: body mass- chest circumference- width of shoulders- body length. The least value for body length is especially expressed because this indicator reflects genetically conditioned peculiarities of growth and development. The rest criteria are more informative as reflecting development of just muscular mass. At the same time values of system formation indicator of hand dynamometry substantially exceed values of main anthropometric indicators. They can be a proof of importance of just arms' strength in martial arts.

It is rather difficult to explain substantial difference between contribution of maximal grab's frequency by right and left hands due to little scope of available information. Such situation justifies detail analysis of available correlation dependences.

Analysis of tapping test results' contribution (see fig.1) permits to speak about different significance of this test's components for functional state. It is confirmed by wave-like character of dynamic of system formation indicator. Coming from quantity of significant correlations, results can be divided into two groups: marginal $(1,5$, and 6$)$ and middle $(2-4)$. With it, first group is characterized by less value. It is connected with adaptation to conditions of test and with complexity of maintaining of high temp of its fulfillment. At the same results of second group can be interpreted as proof of high lability of nervous system of martial art sportsmen, which ensure rather high success in sports.

Considering the purpose of the research it was interesting to analyze the character of dependences between maximal frequency of left and right hands' grabs and other indicators. We determined confident interconnections $(p<0.05)$ between maximal frequency of right hand grab with circumference of right and left wrist $(\mathrm{r}=0.483)$. It reflects direct dependence between development of forearm muscles and ability for maximal quantity of pressing for short times. The presence of these connections permits to offer determination of wrist circumference as screening test, which can be of prognostic importance in martial arts.

Sufficiently high correlation between fulfillment of maximal frequency of right and left hands' grabs ( $\mathrm{r}=0.695)$ shall be interpreted as witness of harmonious physical condition and functional state of the tested sportsmen.

The found dependence on heart beats rate is also interesting $(\mathrm{r}=-0.529)$. The inverse nature of connection in our context can be assessed as witness of stress and time consuming character of the applied methodic.

Analysis of results of test for maximal quantity of left hand pressing in impulse mode showed much higher quantity of correlations. First of all there were more confident correlations with anthropometric indicators, illustrating general physical condition and status of upper limbs. For example, we confirmed confident $(\mathrm{p}<0.05)$ correlations with body mass $(\mathrm{r}=0.648)$, chest circumference (in pause, $\mathrm{r}=0.657$; at inhale $\mathrm{r}=0.646$; at exhale $\mathrm{r}=0.652)$ and width of shoulders $(\mathrm{r}=0,644)$. It confirms again the made earlier assumptions about direct dependence of maximal grab' frequency results on development of muscles.

Analysis of correlations of maximal frequency of left hand grab showed confident correlations with length of right $(\mathrm{r}=0.553)$ and left $(\mathrm{r}=0.529)$ forearms. It illustrates higher importance in comparison with results of right hand test. In our opinion it witnesses about validity of earlier assumption about importance of upper limbs' training for test's efficiency.

One more witness in favor of it is confident correlations with circumferential indicators and results of hand dynamometry. Results of maximal frequency of grab correlated with right arm parameters: circumference of biceps $(\mathrm{r}=0.716)$, forearm $(\mathrm{r}=0.687)$ and wrist $(\mathrm{r}=0.67)$. Correlations with left arm were accordingly: $(\mathrm{r}=0.658),(\mathrm{r}=0.61)$ and $(\mathrm{r}=0.75)$. Value of correlation of grab's maximal frequency with hand dynamometry was at the right $(\mathrm{r}=0.639)$ and at the left ( $\mathrm{r}=0.76)$. Thus, validity of assumption about importance of arm' muscles' development for maximally quick and strong grabs, is confirmed again.

Correlation with systolic blood pressure was higher than with results of maximal frequency of right hand grab $(\mathrm{r}=0.504)$. It must also be interpreted as witness of physical loads stresses' progressing in fulfillment of this test.

Fulfillment of maximal frequency of right hand grabs did not have confident correlations with goniometric indicators. For maximal frequency of left hand grabs we found dependence with bending in right elbow joint $(\mathrm{r}=-0.566)$ 
and moving aside in left wrist joint ( $\mathrm{r}=0.562)$. The latter dependence was the most important: it illustrates connection of muscles, realizing grab and movement.

Assessment of sportsmanship level's correlations with the tested indicators was also of certain interest. We found confident correlations with body mass $(\mathrm{r}=-0.55)$, length of right $(\mathrm{r}=-0.526)$ and left $(\mathrm{r}=-0.49)$ forearms; results of last subtest in tapping test $(\mathrm{r}=-0.503)$, amplitude of moving inside in right wrist joint $(\mathrm{r}=-0.764)$, moving aside in right $(\mathrm{r}=0.573)$ and moving inside in left $(\mathrm{r}=0.508)$ shoulder joints. The presented dependences reflect importance of morphological and functional indicators for success in martial arts.

\section{Discussion}

Comparative analysis of morphological functional characteristics is widely used for analyzing of martial art sportsmen's state. For example Jesu' et al. [9] offered to use mass of free fat, maximal strength in absolute and relative expression, muscular strength, average and peak power in test Wingate, strength of direct and reverse grab as prognostic indictors.

Jagiello et al [5], regarded interconnection of anthropometric indicators with sportsmanship level of elite Polish Judo wrestlers. The authors noted tendency to increase of skeleton mass (width of pelvis, shoulder and elbows) and muscles (diameter of forearm) with rising of sportsmanship. The found correlations of anthropometric indicators with sport rating confirm its objectivity as criterion of wrestlers' skillfulness.

Erkan Demirkan et al. [8] used complex of anthropometrical and functional indicators for comparison of free style and Greco-Rome wrestlers. They determined that arms' peak power, dexterity and flexibility were selective factors of distinctions in these kinds of wrestling.

Researches of Parola F., Musso E. [10] witness about existence of problem of effective criteria's determination in assessment of physical fitness. To large extent this problem is conditioned by specific character of physical qualities' manifestation in competition functioning.

A.V. Voronkov et al. [1] studied the problem of control of power fitness in arm-wrestling. The authors noted authenticity of traditional tests. The received by them results prove demand in accounting of correlation dependences between level of sportsmanship, competition success and fulfillment of tests and control exercises.

Effectiveness of muscular strength's determination in separate movements in wrist joint for prognosis of sportsmen's success in arm-wrestling has been confirmed. Besides, there was established presence of correlation dependences, permitting to assess and prognosticate sportsmen's state [13].

Analyzing morphological predictors of sport talents in female free style wrestling, V.V. Semenov [4] outlines the most informative indicators, which differ, depending on weight categories. They include longitudinal, transversal and circumferential indicators of hip, shin, shoulder and forearm. On the base of them discriminant equations, permitting to prognosticate success, were built.

In this context and on the base of received results we can conclude that maximal frequency of grab is rather important for success of martial art sportsmen. The value of system formation indicator of these criteria (especially for left hand) is comparable with value of important anthropometric indicators (body length). It significantly exceeds contribution to formation of system of tapping test's results. The found indicators of hand dynamometry system formation illustrate that strong grab is very important for martial art wrestlers. This ability is ensured by strength of hand muscles. With it right hand (as stronger one) is characterized by much higher contribution. At the same time system formation indicators has opposite character: value of indicator for right hand is practically three times less than indicator for left hand. May be it is connected with different character of movements in determination of hand dynamometry and maximal frequency of grab. In the first case there takes place maximal static single load, fulfilled during 1-2 second. In the second case mean, multiple dynamic loads take place. It takes much more time. Different values of hand dynamometry precondition different maximal frequencies of grab. With it, the higher static force is, the less dynamic manifestations are. Just it is reflected by opposite values of system formation indicators.

\section{Conclusions}

The conducted researches confirmed presence of correlation dependences between morphological functional indicators of students, who practice martial arts. It has been found that the highest contribution to formation of functional system of sportsmanship growth is made by anthropometrical indicators (body length and mass, chest circumference, hand dynamometry, width of shoulders). At the same time results of test for maximal grab in impulse mode also made substantial contribution to system formation. It is confirmed by presence of great number of correlations. Analysis of 
character, strength and orientation of correlations witnesses about high informative potential of this test. It permits to recommend it as screening in control of sportsmen's, practicing martial arts, state.

\section{References:}

1. Voronkov AV, Nikulin IN, Sobyanin FI. On the improvement of the control force readiness of students engaged arm sport. Physical Education of Students, 2014;2:3-7. http://dx.doi.org/10.6084/m9.figshare.917169

2. Kocharian TN, Krikun EN, Martirosova EG. Osobennosti morfologicheskogo razvitiia vysokokvalificirovannykh basketbolistok razlichnykh igrovykh amplua [Specific features of morphological development of elite female basketball players of different game roles]. VII Mizhnarodnij kongres integrativnoi antropologii, 17-18 zhovtnia 2013 roku [7th International congress of integrative anthropology, October 17-18, 2013], Vinnitsa; 2013. (in Ukrainian)

3. Podrigalo LV, Galashko AI, Lozovoj AD. Sravnitel'naia ocenka antropometricheskogo razvitiia sportsmenov silovykh vidov sporta [Comparative assessment of anthropometrical development of sportsmen of power kinds of sports]. Pedagogics, psychology, medical-biological problems of physical training and sports 2007;3:107 - 111.

4. Semenov VV. Morfologicheskie prediktory sportivnoj odarennosti v zhenskoj vol'noj bor'be [Morphological predictors of sport talents in female free style wrestling]. Mizhnarodnij kongres integrativnoi antropologii, 17-18 zhovtnia 2013 roku [7th International congress of integrative anthropology, October 17th-18th, 2013], Vinnitsa; 2013. (in Ukrainian)

5. Iagello Vladislav, Tkachuk Vladimir, Blakh Veslav. Vzaimosviaz' antropometricheskikh pokazatelej s urovnem sportivnogo masterstva vysokokvalificirovannykh dziudoistov Pol'shi [Interconnection of anthropometrical indicators with sportsmanship level of elite Polish Judo wrestlers]. Fizicheskoe vospitanie studentov tvorcheskikh special'nostej 2004;2:36-45. (in Russian)

6. Iagello Vladislav, Iagello Marina, Kozina ZhL. Profil' stroeniia tela muzhchin, zanimaiushchikhsia bejsbolom [Profile of body composition of men, practicing baseball]. Physical education of students 2012;6:140-143. http://dx.doi.org/10.6084/m9.figshare.96607

7. Baláš J, Pecha O, Martin AJ, \& Cochrane D. Hand-arm strength and endurance as predictors of climbing performance. European Journal of Sport Science, 2011;12(1):16-25. http://dx.doi.org/10.1080/17461391.2010.546431

8. Erkan Demirkan, Mehmet Kutlu, Mitat Koz. Physical Fitness Differences between Freestyle and Greco-Roman Junior Wrestlers Journal of Human Kinetics 2014;41:245-251. http://dx.doi.org/10.2478/hukin-2014-0052.

9. Jesu's Garcı'a-Pallare's, Jose' Marı'a Lo'pez-Gullo'n, Xabier Muriel. Physical fitness factors to predict male Olympic wrestling performance Eur J Appl Physiol 2011;111:1747-1758 http://dx.doi.org/10.1007/s00421-0101809-8.

10. Parola F, Musso E. Market structures and competitive strategies: the carrier-stevedore arm-wrestling in northern European ports. Maritime Policy \& Management. 2007;34(3):259-278. http://dx.doi.org/10.1080/03088830701343369

11. Podrigalo LV, Galashko MN, Galashko NI. Study of specificities of arm wrestlers' psychological status in competition period. Physical Education of Students, 2015;3:44-51. http://dx.doi.org/10.15561/20755279.2015.0306

12. Podrigalo LV, Galashko MN, Galashko NI, Prusik Krzysztof, Cieslicka Miroslawa. Research of hands' strength and endurance indications of arm sport athletes having different levels of skills. Physical Education of Students 2014;2:37-40. http://dx.doi.org/10.6084/m9.figshare.907140.

13. Podrigalo LV, Iermakov SS, Nosko MO, Galashko MN, Galashko NI. Study and analysis of armwrestlers' forearm muscles' strength. Journal of Physical Education and Sport, 2015;15(3):531-537. http://dx.doi.org/10.7752/jpes.2015.03080

14. Podrigalo LV, Istomin AG, Galashko NI. Monitoring of the functional state of the athletes in arm sport. Kharkov: KNMU Publ.; 2010. (in Russian)

15. Tamborini R, Chory RM, Lachlan K, Westerman D, Skalski P. Talking Smack: Verbal Aggression in Professional Wrestling. Communication Studies. 2008;59(3):242-258. http://dx.doi.org/10.1080/10510970802257689

16. Xiong J. The Functions and Methods of Mental Training on Competitive Sports. Physics Procedia. 2012;33(0):20114. 
17. Zaccagni L. Anthropometric characteristics and body composition of Italian national wrestlers. European Journal of Sport Science. 2011;12(2):145-151. http://dx.doi.org/10.1080/17461391.2010.545838

18. Zaporozhanov VA. About reliable indicator of proprioception in agility control. Pedagogics, psychology, medicalbiological problems of physical training and sports 2013;4:21-25. http://dx.doi.org/10.6084/m9.figshare.693023

19. Zaporozhanov VA, Borachinski T. On the transfer of skills skill in different conditions of motor activity. Pedagogics, psychology, medical-biological problems of physical training and sports 2013;9:25-28. http://dx.doi.org/10.6084/m9.figshare.749693

20. Zaporozhanov VA, Boraczynski Tomasz. Discussion on the concepts of "coordination" and "agility" in terms of physical education. Pedagogics, psychology, medical-biological problems of physical training and sports 2015;3:1519. http://dx.doi.org/10.15561/18189172.2015.0303

21. Zosimov AN. Analysis of the systems in medicine. Kharkov: Tornado; 2000. (in Russian) 


\section{Information about the authors:}

Podrigalo L.V.; http://orcid.org/0000-0002-7893-524X; I.podrigalo@mail.ru; Kharkov State Academy of Physical Culture; Klochkovskaya str. 99, Kharkov, 61022, Ukraine.

lermakov S.S.; http://orcid.org/0000-0002-5039-4517; sportart@gmail.com; Kazimierz Wielki University in Bydgoszcz; Sport str. 2, of.209, 85-064 Bydgoszcz, Poland.

Alekseev A.F.; http://orcid.org/0000-0001-8018-170X; I.podrigalo@mail.ru; Kharkov State Academy of Physical Culture; Klochkovskaya str. 99, Kharkov, 61022, Ukraine.

Rovnaya O.A.; http://orcid.org/0000-0003-1519-5632; rovnayaolga@mail.ru; Kharkov State Academy of Physical Culture; Klochkovskaya str. 99, Kharkov, 61022, Ukraine.

Cite this article as: Podrigalo L.V., Iermakov S.S., Alekseev A.F., Rovnaya O.A. Studying of interconnections of morphological functional indicators of students, who practice martial arts. Physical education of students, 2016;1:64-70. doi:10.15561/20755279.2016.0109

The electronic version of this article is the complete one and can be found online at: http://www.sportpedu.org.ua/html/arhive-e.html

This is an Open Access article distributed under the terms of the Creative Commons Attribution License, which permits unrestricted use, distribution, and reproduction in any medium, provided the original work is properly cited (http://creativecommons.org/licenses/by/4.0/deed.en).

Received: 21.01.2016

Accepted: 29.01.2016; Published: 25.02.2016 